\title{
Author Correction: A computationally designed chimeric antigen receptor provides a small-molecule safety switch for T-cell therapy
}

Greta Giordano-Attianese, Pablo Gainza (D), Elise Gray-Gaillard, Elisabetta Cribioli, Sailan Shui, Seonghoon Kim, Mi-Jeong Kwak (D), Sabrina Vollers, Angel De Jesus Corria Osorio, Patrick Reichenbach, Jaume Bonet, Byung-Ha Oh (D, Melita Irving (D), George Coukos and Bruno E. Correia (D)

Correction to: Nature Biotechnology https://doi.org/10.1038/s41587-019-0403-9, published online 3 February 2020.

In the version of this article initially published online, an annotation was missing for authors Melita Irving, George Coukos and Bruno E. Correia: “These authors jointly supervised this work." The error has been corrected in the print, PDF and HTML versions of the article.

Published online: 3 March 2020

https://doi.org/10.1038/s41587-020-0461-z

(๑) The Author(s), under exclusive licence to Springer Nature America, Inc. 2020

\section{Author Correction: Using GlycoDelete to produce proteins lacking plant-specific $\mathrm{N}$-glycan modification in seeds}

Robin Piron, Francis Santens, Annelies De Paepe, Ann Depicker and Nico Callewaert

Correction to: Nature Biotechnology https://doi.org/10.1038/nbt.3359, published online 6 November 2015.

In the version of this article initially published, a grant was missing from the Acknowledgements: N.C. was supported by ERC Consolidator Grant GlycoTarget, grant no. 616966. The error has not been corrected in the original article.

Published online: 5 March 2020

https://doi.org/10.1038/s41587-020-0464-9

() Springer Nature America, Inc. 2020

\section{Author Correction: Template plasmid integration in germline genome-edited cattle}

Alexis L. Norris (D), Stella S. Lee, Kevin J. Greenlees, Daniel A. Tadesse (D, Mayumi F. Miller and Heather A. Lombardi

Correction to: Nature Biotechnology https://doi.org/10.1038/s41587-019-0394-6, published online 7 February 2020.

In the version of this article initially published, an annotation was missing for authors Alexis L. Norris and Stella S. Lee: “These authors contributed equally." The error has been corrected in the HTML and PDF versions of the article.

Published online: 5 March 2020

https://doi.org/10.1038/s41587-020-0467-6

This is a U.S. government work and not under copyright protection in the U.S.; foreign copyright protection may apply 2020 